\title{
CCVII. HYDROGENASE.
}

\section{THE BACTERIAL FORMATION OF METHANE BY THE REDUCTION OF ONE-CARBON COMPOUNDS BY MOLECULAR HYDROGEN.}

\author{
BY MARJORY STEPHENSON \\ AND LEONARD HUBERT STICKLANDי1. \\ From the Biochemical Laboratory, Cambridge.
}

(Received August 18th, 1933.)

The production of methane from a l-carbon compound was first observed by Sohngen in his classical work on methane formation from fatty acids [Sohngen, 1910], calcium formate being quantitatively decomposed to give methane and calcium carbonate. The same culture also effected the reduction of carbon dioxide. It is important to notice that Sohngen worked with mixed cultures which produced methane also from the higher fatty acids. More recently Fischer et al. [1931] have obtained from mud a culture (not claimed by them to be pure) which reduces carbon monoxide to methane, the reaction being accelerated by various colloids. These authors suggest that carbon dioxide is an intermediate product, some evidence being adduced for the occurrence of the reaction

$$
\mathrm{CO}+\mathrm{H}_{2} \mathrm{O} \rightarrow \mathrm{CO}_{2}+\mathrm{H}_{2} \text {. }
$$

They also showed [1932] that if the ratio of carbon monoxide to hydrogen exceeded one-third, carbon dioxide and methane both resulted, while in higher proportions of hydrogen methane alone was produced.

In the work about to be described we have obtained an organism which we believe to be in pure culture. This differs from the mixed cultures of previous workers in attacking, so far as we have been able to observe, only 1-carbon compounds.

\section{The culture.}

The culture used by us was originally obtained from the River Ouse, which had been recently subjected to an influx of fermentable carbohydrate material from a beet-sugar factory and had given a visible fermentation with evolution of gas in the river itself. By subculturing on a medium containing the usual salts [Stephenson, 1930] with $0.5 \%$ formic acid in the form of the sodium salt as the sole source of carbon, and incubating anaerobically, a culture was obtained which decomposed formic acid according to equation (1)

$$
4 \mathrm{H} . \mathrm{COOH} \rightarrow \mathrm{CH}_{4}+3 \mathrm{CO}_{2}+2 \mathrm{H}_{2} \mathrm{O}+39 \mathrm{~kg} \text {. cals. }
$$

The culture was continued on this medium for upwards of three years, involving some hundreds of subcultivations, and there seems to be no doubt that growth depends on the decomposition of the formic acid as above and is not due to any extraneous source of carbon. After a large number of subcultures on this medium 
the culture appeared morphologically homogeneous, but very numerous attempts to get growth on agar plates failed, and the earlier experiments here described were carried out with no certainty as to whether we were dealing with a pure culture or with an association of organisms of similar physiological properties. Subsequently we resorted to the single cell technique ${ }^{1}$ and by this means obtained a culture descended from one cell. The experiments were then repeated with the pedigree culture, the results obtained being identical with those from the crude culture.

As the physiology of the organism is peculiar and not yet fully worked out, we propose to incorporate its full description in a subsequent paper and to confine ourselves here to the chemical aspect of the subject.

\section{Cultivation of the organism.}

In our early experiments we found that very large inoculations (1 cc. in 10) were necessary to get certain growth; later we showed that if the old medium were sterilised by passing through a Seitz filter and added to the new medium at the time of sowing a small inoculation served. Finally we found that the Seitz filtrate could be replaced by sulphide (which it always contained owing to the reduction of sulphate). Our final procedure was as follows. The medium to be inoculated was sterilised by autoclaving; immediately before sowing a solution of sodium sulphide in similar medium readjusted to $p_{\mathrm{H}} 7$ and sterilised by filtration was added, the concentration of the sulphide being arranged to give a final concentration of $0.035 \% \mathrm{Na}_{2} \mathrm{~S}, 9 \mathrm{H}_{2} \mathrm{O}$. Immediately after this addition the culture was inoculated and the anaerobic conditions established; delay results in the rapid oxidation of the sulphide. The culture is able to grow indefinitely without the addition of sulphide, provided the sowings are large enough. This is explained by the fact that the bacteria can reduce the sulphate of the medium to sulphide, as is shown in Exp. 7 on p. 1523. Cysteine and reduced glutathione cannot take the place of sulphide in promoting the growth of the culture.

In order to grow the bacteria in bulk six boiling-tubes each containing $30 \mathrm{cc}$. of medium were first inoculated; when growth was obtained (8 to 14 days) the whole of the contents of the tubes were sown into one litre of medium. A small quantity of sterile mud results in quicker growth at all stages, but is open to the objection that constituents of the mud may be entering into the subsequent reactions. We have tested this point experimentally, and found that the objection is not valid (see Exp. 8, p. 1524); further evidence is given by the fact that identical results are obtained whether the growth of the bacteria has been aided by mud or not. When the culture was well grown, as shown by vigorous effervescence, it was centrifuged and washed with $0.9 \%$ sodium chloride solution or Ringer's solution with full sterile precautions. The growth from one litre of medium was used for each experiment, but it must be realised that the growth is very scanty as compared with that of most organisms grown on broth.

\section{Apparatus.}

This consisted of a bolt-headed flask of about 250 cc. capacity attached to a manometer (see Fig. 1). The method used for sterilisation is fully described in a previous communication [Stephenson and Stickland, 1931, 2].

Exp. 1. The decomposition of formic acid into methane and carbon dioxide. This is the reaction occurring during the growth of the organism on the formate

1 One of us (M. S.) owes Prof.Morton Kahn of Cornell University and his assistant Mrs Schwarzkopf the warmest thanks for instruction and help in the use of this method. 
medium; the quantitative nature of the process was established by the use of washed suspensions as follows.

Into the flask were put $10 \mathrm{cc}$. of phosphate buffer, $p_{\mathrm{H}} 6.4,10 \mathrm{cc}$. of $0.25 \mathrm{~N}$ sodium formate, $10 \mathrm{cc}$. bacterial suspension (from one litre of medium) and $10 \mathrm{cc}$. of water. The flask was then attached to the manometer as previously described; nitrogen passed over heated copper was then introduced and the process repeated. After filling with nitrogen for the second time the manometer was connected to the flask by turning the tap $T_{1}$ and the apparatus placed at $37^{\circ}$. When the manometer reading was constant (after $1 \frac{1}{2}-2$ hours) the initial reading was taken, together with the temperature and pressure. When the reaction was complete (4-5 days), i.e. when no further change of pressure took place, the final readings of manometer, temperature and barometer were taken, and a sample of gas was removed through $\operatorname{tap} T_{3}$ for analysis.

The carbon dioxide remaining bound in the solution as bicarbonate was estimated by acidi-

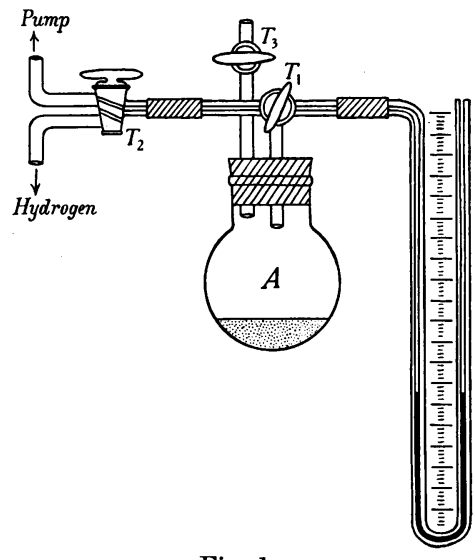

Fig. 1. fying an aliquot part and blowing the carbon dioxide into standard baryta by means of a current of air. The complete figures for one experiment are given in Table I and the results of three similar experiments in Table II.

\section{Table I.}

Formic acid decomposed (mg.)

Volume of gas space of flask (cc.)

Final temperature

Final barometric pressure ( $\mathrm{mm}$.)

Final manometer reading $(\mathrm{mm}$.

Final composition of gas

Final $\mathrm{CO}_{2}$ in solution

Volumes of gas formed at N.T.P. (cc.)

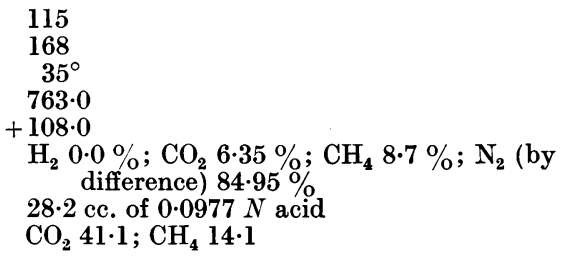

Table II.

\begin{tabular}{|c|c|c|c|c|}
\hline \multirow[b]{2}{*}{$\begin{array}{c}\text { Formic acid } \\
\text { decomposed } \\
\text { (millimols) }\end{array}$} & \multicolumn{2}{|c|}{ Lonte } & \multirow{2}{*}{$\frac{\text { Formic acid }}{4}$} & \multirow{2}{*}{$\frac{\mathrm{CO}_{2} \text { formed }}{3}$} \\
\hline & $\begin{array}{c}\mathrm{CO}_{2} \text { formed } \\
\text { (millimols) }\end{array}$ & $\begin{array}{c}\mathrm{CH}_{4} \text { formed } \\
\text { (millimols) }\end{array}$ & & \\
\hline $2 \cdot 00$ & 1.53 & $0 \cdot 46$ & 0.50 & 0.51 \\
\hline $2 \cdot 00$ & $1 \cdot 47$ & 0.45 & 0.50 & 0.49 \\
\hline $2 \cdot 50$ & $1 \cdot 83$ & $0 \cdot 63$ & 0.625 & 0.61 \\
\hline
\end{tabular}

Thus a washed suspension of the culture decomposes formic acid quantitatively in accordance with equation (1) (p. 1517). (The last two columns in Table II are added to show the extent of the agreement more clearly.)

Exp. 2. The reduction of carbon dioxide by hydrogen to methane. We next investigated whether the culture responsible for the reaction described in the last section could also effect the reduction of carbon dioxide to methane by molecular hydrogen, as Sohngen's did. The same apparatus was used and in the flask were placed $10 \mathrm{cc}$. buffer $p_{\mathrm{H}} 7 \cdot 0,10 \mathrm{cc}$. bacterial suspension and $20 \mathrm{cc}$. water. After connection to the manometer, the flask was evacuated; pure carbon dioxide from a Kipp's apparatus was then let in to a pressure of about $60 \mathrm{~mm}$. 
(bringing the $p_{\mathrm{H}}$ of the solution to $6 \cdot 5$, the optimum), and this pressure was read off accurately on the manometer attached to the pump; the flask was then completely filled with pure hydrogen, and the tap turned to connect it with its own manometer. Finally, the manometer readings, the barometric pressure and the room temperature were taken; from these data the absolute volumes of carbon dioxide and hydrogen in the flask could be calculated. The whole apparatus was then placed at $37^{\circ}$, and when the uptake of gas had finished (in about 6 days) the temperature and manometer and barometer readings were again taken and a sample of gas withdrawn for analysis. The complete results of a typical experiment are given in Table III, and the condensed results of four experiments in Table IV.

\section{Table III.}

$\begin{array}{lccc}\text { Original pressure of } \mathrm{CO}_{2} \text { (mm.) } & 65 \cdot 5 & & \\ \text { Volume of gas space in flask (cc.) } & 176 & & \\ \text { Final composition of gas } & \mathrm{CO}_{2} 0 \cdot 0 \% ; \mathrm{H}_{2} & 86 \cdot 7 \% ; \mathrm{CH}_{4} 13.5 \% \\ & \text { Initial } & \text { Final } & \text { Difference } \\ \text { Temperature } & 20^{\circ} & 36^{\circ} & \\ \text { Barometric pressure (mm.) } & 757 \cdot 5 & 761 \cdot 5 & \\ \text { Manometer reading (mm.) } & +19.5 & -198 \cdot 5 & \\ \text { Volume of } \mathrm{CO}_{2} \text { at N.T.P. (cc.) } & 14 \cdot 2 & 0 \cdot 0 & -14 \cdot 2 \\ \text { Volume of } \mathrm{H}_{2} \text { at N.T.P. (cc.) } & 150 \cdot 0 & 92 \cdot 0 & -58 \cdot 0 \\ \text { Volume of } \mathrm{CH}_{4} \text { at N.T.P. (cc.) } & 0.0 & 14 \cdot 3 & +14 \cdot 3\end{array}$

Table IV.

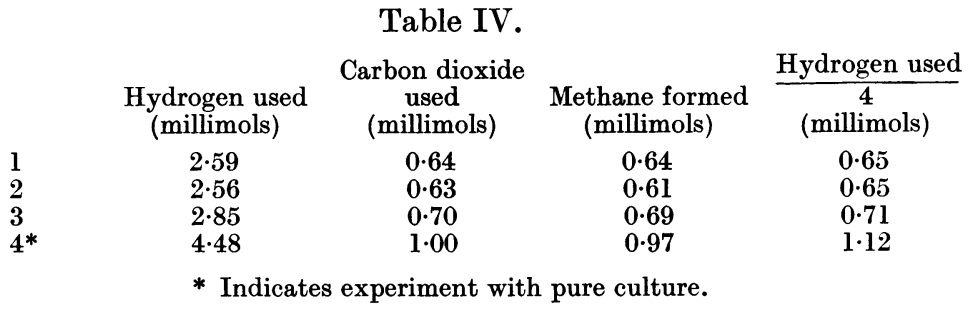

The theoretical equation is

$$
\mathrm{CO}_{2}+4 \mathrm{H}_{2} \rightarrow \mathrm{CH}_{4}+2 \mathrm{H}_{2} \mathrm{O}
$$

and the results obtained agree with this, so we must conclude that the same culture which decomposes formic acid to methane and carbon dioxide is also capable of reducing carbon dioxide to methane by means of molecular hydrogen.

It will be remembered that Sohngen carried out the fermentation of a number of fatty acids in the presence of hydrogen and obtained greater yields of methane with uptake of hydrogen. We therefore allowed our culture to decompose formate in an atmosphere of hydrogen, and estimated the methane formed and the hydrogen used.

Exp. 3. The reduction of formic acid with hydrogen. The same method was used as in Exp. 1, but only 5 cc. of $0 \cdot 25 N$ formate were taken, and the apparatus was filled with hydrogen. After about six days there was no further movement of the manometer, and the usual readings were taken, a sample of gas was withdrawn and the residual formic acid estimated. The results of three experiments are given in Table VI, with complete details of one of them in Table V.

The equation is

$$
\mathrm{H} . \mathrm{COOH}+3 \mathrm{H}_{2} \rightarrow \mathrm{CH}_{4}+2 \mathrm{H}_{2} \mathrm{O}
$$

From these experiments it is clear that if the change of formic acid into methane is carried out in an atmosphere of hydrogen no carbon dioxide is produced, but the carbon of the formic acid is completely reduced to methane. 
Table V.

Formic acid decomposed (mg.)

Volume of gas space in flask (cc.)

Final composition of gas

Temperature

Barometric pressure (mm.)

Manometer reading $(\mathrm{mm}$.

Volume of $\mathrm{H}_{2}$ at N.T.P. (cc.)

Volume of $\mathrm{CH}_{4}$ at N.T.P. (cc.)
$56 \cdot 2$

170

$\mathrm{H}_{2} 72.6 \% ; \mathrm{CH}_{4} 27.4 \%$

$\begin{array}{rrr}\text { Initial } & \text { Final } & \text { Difference } \\ 36^{\circ} & 36^{\circ} & \\ 767 \cdot 0 & \mathbf{7 4 3 \cdot 5} & \\ +36 \cdot 0 & -227 \cdot 5 & \\ 150 \cdot 0 & 69 \cdot 0 & -81 \cdot 0 \\ 0 \cdot 0 & 26 \cdot 0 & +26 \cdot 0\end{array}$

Table VI.

\begin{tabular}{|c|c|c|c|c|}
\hline & $\begin{array}{c}\text { Formic acid } \\
\text { decomposed } \\
\text { (millimols) }\end{array}$ & Hydrogen used & $\begin{array}{l}\text { Methane formed } \\
\text { (millimols) }\end{array}$ & $\frac{\text { Hydrogen used }}{3}$ \\
\hline $\begin{array}{l}1 \\
2 \\
3^{*}\end{array}$ & $\begin{array}{l}1 \cdot 22 \\
1 \cdot 25 \\
1 \cdot 11\end{array}$ & $\begin{array}{l}3 \cdot 62 \\
3 \cdot 91 \\
3 \cdot 36\end{array}$ & $\begin{array}{l}1 \cdot 16 \\
1 \cdot 22 \\
1 \cdot 16\end{array}$ & $\begin{array}{l}1 \cdot 21 \\
1 \cdot 30 \\
1 \cdot 12\end{array}$ \\
\hline
\end{tabular}

Exp. 4. The reduction of carbon monoxide by hydrogen to methane. The usual phosphate buffer and cell suspension were placed in the flask in a total volume of 40 cc., and the flask was evacuated and filled with a gas mixture containing about $95 \%$ hydrogen and $5 \%$ carbon monoxide, accurately analysed in the Haldane apparatus. The gas was freed from oxygen first by heating a coil of platinum wire in it and then by bubbling it through alkaline pyrogallol on its way to the flask; the former of these two treatments reduced the oxygen content below that detectable in the Haldane apparatus, viz. $0.02 \%$. When the apparatus was incubated at $37^{\circ}$, the gas volume diminished rather slowly, and after several weeks the hydrogen uptake stopped considerably short of the theoretical amount. At the end of the experiment the usual readings were taken, and a sample of gas was withdrawn for estimation of hydrogen, carbon monoxide and methane.

The distinction between carbon monoxide and methane in this mixture depended on the estimation of the oxygen remaining after burning the gas, and as the total amount of $\left(\mathrm{CO}+\mathrm{CH}_{4}\right)$ was only roughly $6 \%$ of the gas, and the analyses had to be done on samples of $0.8 \mathrm{cc}$., the results were less accurate than usual. These particular gas samples were always analysed in triplicate, and the values agreed as well as could be expected. Further, a mixture of carbon monoxide and hydrogen, containing no methane, on analysis by this method, gave values for methane between $+0.1 \%$ and $-0.5 \%$.

Table VII. Analyses of mixture of $\mathrm{H}_{2}$ and $\mathrm{CO}$, to test accuracy of analyses of mixtures of $\mathrm{H}_{2}, \mathrm{CO}$ and $\mathrm{CH}_{4}$.

(1) (2)

(a) By ordinary method

$\begin{array}{ccc} & (1) & (2) \\ & \% & \% \\ \mathrm{H}_{2} & \mathbf{8 0 \cdot 9} & \mathbf{8 0 \cdot 3} \\ \mathrm{CO} & \frac{19 \cdot 1}{100 \cdot 0} & \underline{\mathbf{1 9 \cdot 4}} \\ & \frac{99 \cdot 7}{100}\end{array}$

(b) By special method

The results of experiments on the reduction of carbon monoxide are given in Tables VIII and IX. The equation representing the reaction is

$$
\mathrm{CO}+3 \mathrm{H}_{2} \rightarrow \mathrm{CH}_{4}+\mathrm{H}_{2} \mathrm{O}
$$


and the results are sufficiently close to show that this is actually the reaction that takes place; the experimental error is greater than in the previous experiments.

Table VIII.

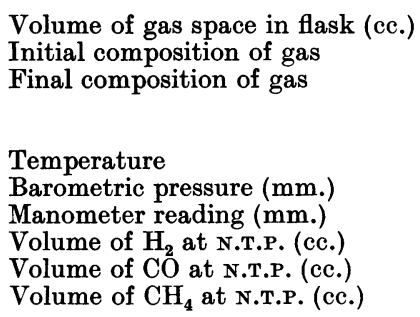

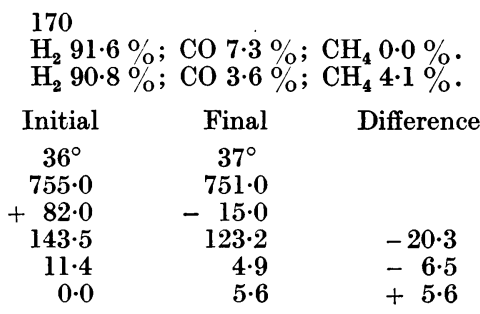

Table IX.

$\begin{array}{ccc}\text { CO reduced } & \begin{array}{c}\mathrm{CH}_{4} \text { produced } \\ \text { (millimols) }\end{array} & \frac{\mathrm{H}_{2} \text { used }}{3} \\ 0 \cdot 29 & 0 \cdot 25 & \text { (millimols) } \\ 0 \cdot 18 & 0 \cdot 175 & 0 \cdot 30 \\ & & 0 \cdot 20\end{array}$

* Indicates experiment with pure culture.

Exp. 5. The reduction of formaldehyde by hydrogen. Formaldehyde is far too toxic for use in our apparatus, as the smallest amount the reduction of which could be measured would be sufficient to kill the bacteria and destroy their enzymes. The only possibility was to use some very slightly dissociated compound of formaldehyde, such as hexamethylenetetramine, and this was done.

$10 \mathrm{cc}$. of $0.63 \%$ hexamethylenetetramine were placed in the flask with the usual buffer and bacterial suspension in a total volume of $40 \mathrm{cc}$., and the apparatus was filled with hydrogen and incubated at $37^{\circ}$. Hydrogen uptake continued for two to three weeks, when the gas was analysed and the remaining hexamethylenetetramine estimated. This was done by converting the hexamethylenetetramine into formaldehyde by treatment with dilute sulphuric acid, allowing the aldehyde to react with sodium bisulphite (in excess) and titrating the bound sulphite with standard iodine in the usual way. The method is unsatisfactory, owing to the fact that the reaction of hexamethylenetetramine with dilute acids produces, besides formaldehyde and ammonia, methylamine, dimethylamine and other products; too low results in the initial and final hexamethylenetetramine estimations would partly account for the low value for "formaldehyde reduced."

The results (Tables $\mathrm{X}$ and $\mathrm{XI}$ ) are sufficient to show that the reaction

does really occur.

$$
\mathrm{H} . \mathrm{CHO}+2 \mathrm{H}_{2} \rightarrow \mathrm{CH}_{4}+\mathrm{H}_{2} \mathrm{O}
$$

Table X.

Formaldehyde disappeared (mg.)

Volume of gas space in flask (cc.)

Final composition of gas

Temperature

Barometric pressure (mm.)

Manometer reading $(\mathrm{mm}$.

Volume of $\mathrm{H}_{2}$ at N.T.P. (cc.)

Volume of $\mathrm{CH}_{4}$ at N.T.P. (cc.)

$\begin{array}{ccc}40 & & \\ 162 & & \\ \mathrm{H}_{2} 70 \cdot 1 \% & \mathrm{CH}_{4} 29 \cdot 8 \% & \\ \text { Initial } & \text { Final } & \text { Difference } \\ 35^{\circ} & 37^{\circ} & \\ 764 \cdot 0 & 769 \cdot 0 & \\ +81 \cdot 0 & -146 \cdot 0 & \\ 151 \cdot 4 & 73.5 & -75 \cdot 9 \\ 0.0 & 32 \cdot 1 & +32 \cdot 1\end{array}$




\begin{tabular}{|c|c|c|c|c|}
\hline & $\begin{array}{c}\text { Formaldehyde } \\
\text { reduced } \\
\text { (millimols) }\end{array}$ & $\begin{array}{c}\text { Hydrogen used } \\
\text { (millimols) }\end{array}$ & $\begin{array}{l}\text { Methane formed } \\
\text { (millimols) }\end{array}$ & $\frac{\frac{\mathrm{H}_{2} \text { used }}{2}}{\text { (millimols) }}$ \\
\hline $\begin{array}{l}1 \\
2 *\end{array}$ & $\begin{array}{l}1 \cdot 34 \\
0 \cdot 215\end{array}$ & $\begin{array}{l}3 \cdot 39 \\
0 \cdot 46\end{array}$ & $\begin{array}{l}1 \cdot 43 \\
0 \cdot 20\end{array}$ & $\begin{array}{l}1 \cdot 69 \\
0 \cdot 23\end{array}$ \\
\hline
\end{tabular}

Exp. 6. The reduction of methyl alcohol to methane by hydrogen. This was carried out in the usual way except that special precautions were taken to avoid loss of methyl alcohol vapour during the evacuation of the flask. $10 \mathrm{cc}$. of buffer at $p_{\mathrm{H}} 6 \cdot 3,7 \mathrm{cc}$. of water and 20 cc. of bacterial suspension were placed in the flask, which was then twice evacuated and filled with hydrogen, leaving at the end a diminished pressure of about $20 \mathrm{~mm}$. of mercury. 1 cc. of the methyl alcohol solution was then added through the tap, care being taken that no air was admitted, and washed down twice with 1 cc. of water, and the flask was then completely filled with hydrogen and the whole apparatus incubated at $37^{\circ}$. Theoretically, if the reaction taking place is

$$
\mathrm{CH}_{3} \mathrm{OH}+\mathrm{H}_{2}=\mathrm{CH}_{4}+\mathrm{H}_{2} \mathrm{O}
$$

no change of pressure should occur. The results are given in Tables XII and XIII; in Exps. 1 and 2 excess of methyl alcohol was present, and the amount left was not estimated, but the agreement between hydrogen used and methane formed is good, and in Exp. 3 the methyl alcohol was completely accounted for as methane.

Table XII.

$\begin{array}{ccc}180 & & \\ \mathrm{H}_{2} 91.2 \% & \mathrm{CH}_{4} 8 \cdot 6 \% & \\ \text { Initial } & \text { Final } & \text { Difference } \\ 34^{\circ} & 36^{\circ} & \\ 753 \cdot 0 & 761 \cdot 0 & \\ +74 \cdot 0 & +73 \cdot 0 & \\ 165 \cdot 5 & 151 \cdot 0 & -14 \cdot 5 \\ 0 \cdot 0 & 14 \cdot 2 & +14 \cdot 2\end{array}$

Table XIII.

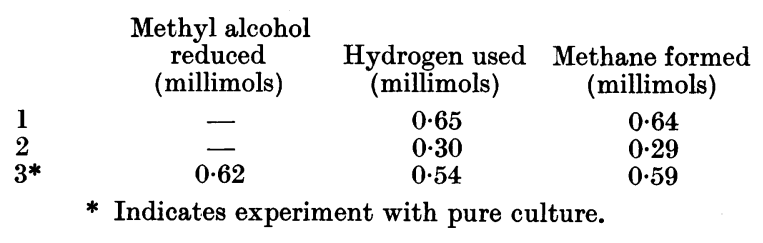

Exp. \%. The reduction of sulphate to sulphide by hydrogen. This experiment was carried out in the same way as those previously described [Stephenson and Stickland, 1931, 2]. The results show that the methane-forming culture can also carry out the reaction

$$
\mathrm{H}_{2} \mathrm{SO}_{4}+4 \mathrm{H}_{2}=\mathrm{H}_{2} \mathrm{~S}+4 \mathrm{H}_{2} \mathrm{O} \text {. }
$$

The experimental results are summarised in Table XIV.

\begin{tabular}{cccc}
\multicolumn{2}{c}{ Table XIV. } \\
$\begin{array}{c}\mathrm{Na}_{2} \mathrm{SO}_{4} \text { reduced } \\
\text { (millimols) }\end{array}$ & $\begin{array}{c}\text { Hydrogen used } \\
\text { (millimols) }\end{array}$ & $\frac{\mathrm{H}_{2} \text { used }}{4}$ & $\begin{array}{c}\text { Hydrogen sulphide } \\
\text { formed } \\
\text { (millimols) }\end{array}$ \\
0.42 & $1 \cdot 60$ & 0.40 & 0.35
\end{tabular}


Exp. 8. Control. The bacteria from a litre of medium together with the mud of the medium on which they had grown were placed in the manometer apparatus as usual, but without the addition of any carbon compound. After incubation with hydrogen for fourteen days no methane was found in the gas, showing that the results of the quantitative experiments are not invalidated by the presence of mud. This result received confirmation in experiments in which various 2-carbon compounds were added and in which no methane was formed.

\section{Experiments on reaction velocity.}

Of the six reactions described in which carbon compounds are converted into methane, the three involving carbon dioxide and formic acid proceed easily and rapidly and are completed in our manometer apparatus in a few days. The reductions of carbon monoxide, formaldehyde and methyl alcohol, on the other hand, are relatively very slow and are usually incomplete in twenty-one days, even with low initial concentrations. This difference of velocity has been confirmed by experiments in Barcroft apparatus, in which a thick suspension of bacteria (pure culture) was allowed to act on carbon dioxide, formic acid, hexamethylenetetramine and methyl alcohol in an atmosphere of hydrogen. The substrate concentration was in each case $N / 30$, and the $p_{\mathrm{H}} 6 \cdot 5$; for carbon dioxide the $p_{\mathrm{H}}$ was adjusted by using a mixture of $50 \%$ hydrogen and $50 \%$ carbon dioxide in equilibrium with $N / 30$ sodium bicarbonate. The results showed that formic acid and carbon dioxide are reduced at roughly the same rate, while hexamethylenetetramine is reduced at a rate too slow for measurement in the conditions of such experiments. Values for the rate of reaction in terms of the dry weight of bacteria present cannot be given, as the suspension of bacteria is always mixed with a small amount of mud which makes estimations of dry weight or nitrogen content useless.

In these experiments the reaction curve starts immediately in a straight line, which-especially in the case of a very slow-growing organism-precludes the idea that cell multiplication is interfering appreciably with the results.

\section{Experiments on the course of the reactions.}

The mechanism involved in the production of methane from these compounds must now be considered. The decomposition of formic acid into hydrogen and carbon dioxide $\left(\mathrm{H} . \mathrm{COOH} \rightarrow \mathrm{H}_{2}+\mathrm{CO}_{2}\right)$ is a common property of many organisms and has recently been shown to be due to a particular enzyme (formic hydrogenlyase) distinct from formic dehydrogenase catalysing the reaction $\mathrm{H}$. $\mathrm{COOH} \rightarrow 2 \mathrm{H}+\mathrm{CO}_{2}$ [Stephenson and Stickland, 1932]. An organism possessing this enzyme together with hydrogenase (activating molecular hydrogen) [Stephenson and Stickland, 1931, l] and at the same time capable of reducing carbon dioxide might well bring about reaction (1) (p. 1517) in a stepwise manner, by the preliminary decomposition of formic acid into carbon dioxide and hydrogen, followed by a reduction of carbon dioxide by hydrogen as in reaction (2) (p. 1520). Our organism possesses hydrogenase, as is shown by the reduction of methylene blue by hydrogen with a suspension of washed cells:

$$
\begin{array}{lc}
1 \text { cc. } 1 / 5000 \text { methylene blue, } p_{\mathrm{H}} 6 \cdot 3 \text {, in vacuo } & \begin{array}{c}
\text { Reduction time } \\
\text { (min.) }
\end{array} \\
\text { l cc. } 1 / 5000 \text { methylene blue, } p_{\mathrm{H}} 6 \cdot 3 \text {, in hydrogen } & >60
\end{array}
$$

Moreover, we have obtained evidence for the presence of formic hydrogenlyase; a series of test-tubes containing Durham tubes and formic inorganic medium was 
sown in the usual way and gas withdrawn from the Durham tubes for analysis at different stages in the growth of the culture. It is seen from the figures in Table XV that in the early stages hydrogen as well as methane was present, but that if the reaction was allowed to continue methane alone was the final product.

Table XV.

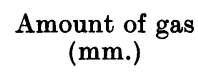

31

$\begin{array}{cc}\mathrm{CH}_{4} \% & \mathrm{H}_{2} \% \\ 64 & 36 \\ 86 & 14 \\ 92 & 8 \\ 71 & 29 \\ 98 \cdot 5 & 1.5 \\ 99.5 & 0.5\end{array}$

The extent of growth of the culture was measured by the length of the column of gas in the Durham tube, given in the Table in $\mathrm{mm}$.

The same conclusion was reached from experiments carried out in Barcroft manometers. A thick cell suspension was shaken in this apparatus with $M / 10$ formate in buffer at $p_{\mathrm{H}} 6.5$ in an atmosphere of nitrogen; the results showed a brief rapid evolution of gas followed by a slower prolonged evolution. When the gas in the cups was analysed at the end of the first period it was found to contain (besides nitrogen) mainly hydrogen and carbon dioxide with a little methane; after further reaction had taken place the analysis showed decreased hydrogen and carbon dioxide and increased methane.

\section{Analysis of gas in Barcroft cups.}

$\begin{array}{lcccc} & \begin{array}{c}\text { Total } \\ \text { evolution } \\ \text { mm. }\end{array} & \mathrm{H}_{2} \% & \mathrm{CO}_{2} \% & \mathrm{CH}_{4} \% \\ \text { After 1 hour } & \mathbf{4 4 8} & \mathbf{0 . 9} & \mathbf{1} \cdot 1 & \mathbf{0} \cdot 1 \\ \text { After 26 hours } & \mathbf{1 6 6 6} & \mathbf{0 \cdot 6} & \mathbf{0 \cdot 3} & \mathbf{3 . 9}\end{array}$

This suggests that formic acid undergoes a preliminary decomposition to carbon dioxide and hydrogen, and methane is then synthesised by reaction (2) (p. 1520). This would involve, not a direct reduction of formic acid, but a reduction by excess hydrogen of the carbon dioxide produced in the first reaction. It must be admitted, however, that we are offering here a plausible hypothesis and no proof.

In respect of reactions (4), (5) and (6) (pp. 1521, 1522 and 1523 respectively) we are in the dark. Possibly a preliminary reduction of all three initial compounds to formic acid and a decomposition of this first to carbon dioxide and hydrogen and thence to methane is as plausible as any. It should be noted that recent workers [Fischer et al., 1932], have suggested that in the case of carbon monoxide a decomposition of water takes place thus

$$
\mathrm{CO}+\mathrm{H}_{2} \mathrm{O} \rightarrow \mathrm{CO}_{2}+\mathrm{H}_{2} \text {. }
$$

Their evidence rests on the appearance of $13.4 \mathrm{cc}$. of hydrogen in a bacterial decomposition of $1100 \mathrm{cc}$. of carbon monoxide in the presence of mud, giving $323 \mathrm{cc}$. of methane and $724 \mathrm{cc}$. of carbon dioxide. Without a control experiment 
in nitrogen no evidence exists to decide whether carbon monoxide is transformed to methane via this reaction

or by hydration to formic acid

$$
\mathrm{CO}+\mathrm{H}_{2} \mathrm{O} \rightarrow \mathrm{CO}_{2}+\mathrm{H}_{2}
$$

$$
\mathrm{CO}+\mathrm{H}_{2} \mathrm{O} \rightarrow \mathrm{H} . \mathrm{COOH} \text {. }
$$

As an alternative it is possible that formic acid is a stage in the reduction of carbon dioxide to methane by a stepwise process thus:

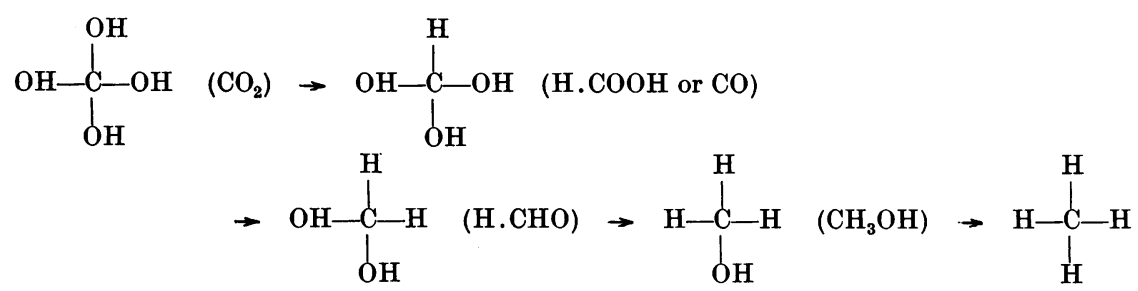

On this view formic hydrogenlyase would be competing with the enzyme concerned in the reduction of formic acid, and the hydrogen produced by its action in the initial stages would be finally used up again in the reduction.

\section{The reduction of other carbon compounds.}

We have shown that five simple l-carbon compounds are reduced by our organism to methane. On the other hand the following compounds were not attacked: acetic, propionic, butyric and caprylic acids (which were all decomposed to methane and carbon dioxide by Sohngen's mixed culture), ethyl alcohol, acetaldehyde and glucose. These compounds were tested in conditions where they formed the sole source of carbon for the organism, and also in broth cultures; in the former case no growth occurred, and in the latter the bacteria grew on the broth but failed to produce any methane from the added compound. In addition acetic acid, acetaldehyde and ethyl alcohol were tested in the manometer apparatus, with washed suspensions, with negative results. As far as we have tested, therefore, only compounds with one carbon atom are reduced by our culture.

\section{SUMmaRY.}

1. An organism has been isolated by the single cell technique which is able to live anaerobically on an inorganic medium with formate as sole source of carbon.

2. The formic acid is decomposed as follows:

$$
4 \mathrm{H} . \mathrm{COOH}=\mathrm{CH}_{4}+3 \mathrm{CO}_{2}+2 \mathrm{H}_{2} \mathrm{O}+39 \mathrm{~kg} \text {. cals. }
$$

This reaction has been shown to occur in two stages, viz.

(1) $\mathrm{H} . \mathrm{COOH}=\mathrm{H}_{2}+\mathrm{CO}_{2}$,

and (2) $4 \mathrm{H}_{2}+\mathrm{CO}_{2}=\mathrm{CH}_{4}+2 \mathrm{H}_{2} \mathrm{O}$,

and is therefore the work of two enzymes, formic hydrogenlyase (1) and hydrogenase (2) with an additional mechanism for the activation of carbon dioxide as a hydrogen acceptor.

3. The organism (tested in washed suspensions) reduces the following 1-carbon compounds to methane by means of molecular hydrogen (i.e. hydro- 


\section{BACTERIAL FORMATION OF METHANE}

genase reactions): carbon dioxide, formic acid, carbon monoxide, formaldehyde (as hexamethylenetetramine) and methyl alcohol.

4. No compounds so far tested containing more than one carbon atom are reduced by this organism with production of methane.

We take this opportunity of thanking Sir Frederick Hopkins for his interest in this work.

\section{REFERENCES.}

Fischer, Lieske and Winzer (1931). Biochem. Z. 236, 247.

(1932). Biochem. Z. 245, 2.

Sohngen (1910). Rec. Trav. Chim. Pays Bas. 29, 238.

Stephenson (1930). Bacterial metabolism (Longmans, London).

—— and Stickland (1931, 1). Biochem. J. 25, 205.

- (1931, 2). Biochem. J. 25, 215.

(1932). Biochem. J. 26, 712 . 